Check for updates

Cite this: J. Anal. At. Spectrom., 2020 35,1956

Received 4th May 2020

Accepted 17th June 2020

DOI: 10.1039/d0ja00210k

rsc.li/jaas

\title{
High-speed photographic study of vaporclouds from wet droplets and the subsequent solid particles in an inductively coupled plasma $\uparrow$
}

\author{
Christopher H. Ebert, \$§ Nathan J. Saetveit, (DD $\$ \uparrow$ Stanley J. Bajic, (D) Daniel S. Zamzow, \\ David P. Baldwin\| and R. S. Houk (D)*
}

\begin{abstract}
Movies of an inductively coupled plasma (ICP) while nebulizing a concentrated sample of yttrium were recorded using a high-speed camera with short exposure time (10 $\mu \mathrm{s})$ and fast framing rate (5000 frames per s). Clouds from large droplets can be seen in several successive frames as they travel downstream in the axial channel of the ICP. These droplet clouds are superimposed on the usual spatial structure of red $Y O$, neutral $Y$ atom and blue $Y^{+}$emission. As a particular large droplet moves downstream, its red emission cloud evolves into a faint white streak with a surrounding cloud of blue $\mathrm{Y}^{+}$emission. The streak is attributed to a solid residue from the droplet. The velocity of the droplet and subsequent particle is measured to be $28 \mathrm{~m} \mathrm{~s}^{-1}$. The general characteristics of the droplet and particle clouds agree well with previous photographic measurements and those by other methods such as laser induced-fluorescence or scattering
\end{abstract}

\section{Introduction}

The behavior of wet droplets and the resulting solid analyte particles in high-temperature atom and atomic ion sources has been an ongoing interest of Prof. Gary Hieftje throughout his career. ${ }^{1-3}$ A number of other investigators have also studied these phenomena, notably Olesik, ${ }^{4,5}$ Farnsworth, ${ }^{6}$ Montaser $^{7}$ and their co-workers. Recent fundamental experimental studies of dried solid particles by Niemax, ${ }^{8}$ Günther ${ }^{9}$ and co-workers, along with simulations by Bogaerts' group, ${ }^{10,11}$ have continued this theme. The work of Tanner et al..$^{12,13}$ on mass cytometry of intact biological cells draws from this basic work, as cells apparently vaporize, atomize and ionize with reasonable efficiency in an otherwise standard ICP. ${ }^{14}$ Recent work on determining the elemental composition and size distributions of intact solid nanoparticles ${ }^{15-20}$ follows a related theme. The

\footnotetext{
Ames Laboratory U. S. Department of Energy, Department of Chemistry, Iowa State University, Ames, IA 50011, USA. E-mail: rshouk@iastate.edu; Tel: +1-515-450-3672 $\dagger$ Electronic supplementary information (ESI) available: Video 1. High-speed movie of ICP during nebulization and introduction of $10000 \mathrm{ppm} \mathrm{Y} \mathrm{in} 1 \%$ aqueous nitric acid. Arrows denote two different large droplets and subsequent particle events. Framing rate 5000 frames per s, time between frames $200 \mu \mathrm{s}$, exposure time $10 \mu$ s. See DOI: $10.1039 / \mathrm{d} 0 \mathrm{ja} 00210 \mathrm{k}$

\$ These authors contributed equally to this work.

$\S$ Present address: Center for Ecosystem Science and Society, Northern Arizona University, Flagstaff, AZ 86004, USA.

I Present address: Elemental Scientific Inc., Omaha, NE 68122, USA.

|| Present address: Special Technologies Laboratory, Nevada National Security Site, Santa Barbara, CA 93111, USA.
}

behavior of discrete sample segments in the ICP is key to the success of these recent studies.

The author's group has contributed to droplet and particle studies via high-speed photographic experiments. Previous work used photographic film ${ }^{21-23}$ and then a high-speed digital camera. ${ }^{24}$ These prior studies used cameras with fast shutter speeds but slow framing rates. They could capture isolated pictures of individual droplets or particles but could not follow a particular droplet or particle during its entire journey through the ICP.

The present paper uses an improved camera with both high shutter speed and fast framing rate. The resulting movies show the successive development of vaporization, atomization, excitation and ionization during the path of a droplet or particle through the ICP. The present paper describes these events for large wet droplets from a conventional pneumatic nebulizer, which remains the most widespread mode of sample introduction into the ICP. Both mass cytometry and nanoparticle size/composition measurements rely on such nebulizers.

\section{Experimental section}

The ICP (RF Plasma Products ICP-16L, $40 \mathrm{MHz}$ ) was similar to, but not the same device as that used in our previous photographic studies. ${ }^{23,24}$ The Fassel torch ${ }^{25}$ was $20 \mathrm{~mm}$ OD with a tubular injector, tip dimensions $1.5 \mathrm{~mm}$ ID $\times 15 \mathrm{~mm}$ long. Other operating conditions were: forward power $1.1 \mathrm{~kW}$, outer gas flow rate $15.0 \mathrm{~L} \mathrm{~min}^{-1}$, and auxiliary gas flow rate 0.5 $\mathrm{L} \min ^{-1}$. 
A concentric pneumatic nebulizer (Meinhard Type C) was pumped at a very fast uptake rate $\left(1.9 \mathrm{~mL} \mathrm{~min}^{-1} v s\right.$. the common $\left.\sim 0.5 \mathrm{~mL} \min ^{-1}\right)$. At high liquid flow rate this nebuilzer produced lots of large droplets, likely due to condensation of the initial droplets, as demonstrated by Montaser et al. ${ }^{26}$ The aerosol gas flow rate was $0.65 \mathrm{~L} \mathrm{~min}^{-1}$. A Scott-type double-pass spray chamber ${ }^{25}$ was used.

The ICP was operated vertically with no mass spectrometer (MS) sampling cone. This allowed observation of the droplets for a long pathlength extending well beyond the end of the torch. The sample was a concentrated solution of yttrium at $10000 \mathrm{ppm}$ in 1\% aqueous nitric acid. Yttrium was chosen because the emission of excited YO (deep red), neutral Y atoms (pale red or pink), and $\mathrm{Y}^{+}$ions (blue) can be readily distinguished visually.

An Olympus i-Speed 2 video camera (Olympus Corp., Tokyo, Japan) captured videos and images of the ICP, including droplets and particles therein. A $25 \mathrm{~mm}$ focal-length lens (Navitron) focused light from the plasma onto the camera. Images were recorded at 5000 frames per s $(320 \times 240$ pixels $)$. A shutter was used to shorten the exposure time to $10 \mu \mathrm{s}$.

\section{Results and discussion}

Video 1 in the ESI section $\uparrow$ shows an entire clip taken under the conditions described above. As described by Koirtyohann et al. ${ }^{27}$ the usual dark axial channel, red initial radiation zone (IRZ) and blue normal analytical zone (NAZ) are visible. This IRZ and NAZ structure is present in every frame and results from small- or medium-size droplets that desolvate, vaporize, atomize etc. upstream in the axial channel of the plasma. The analyte signals in an emission or MS experiment result from such droplets. The emission clouds from large droplets and particles are observed as perturbations on this background structure.

In the subsequent discussion, spatial locations in the plasma are referred to by the phrases "upstream" (i.e., down in Video $1 \dagger$ ) or "downstream" (up in Video $1 \dagger$ ). This terminology is preferred to traditional phrases like "above" or "below" the load coil, which are inaccurate for the horizontal plasmas usually used in ICP-MS or ICP emission spectrometry with axial viewing.

The torch ID is $18 \mathrm{~mm}$. The farthest upstream section of the plasma is approximately $16 \mathrm{~mm}$ wide. Red clouds from intact droplets can be seen periodically passing through the plasma. Some of these droplets persist for the entire length of the plasma. These droplet clouds resemble those reported in our previous paper $^{24}$ but are more frequent and dramatic in the present work, presumably due to the present use of very high liquid uptake rate to enhance production of large droplets.

A set of sequential frames from Video $1 \dagger$ that illustrates the time development of droplet/particle clouds is shown in Fig. 1. This sequence is typical of many we observed throughout the video. In Frame 690, a large droplet is leaving the tip of the IRZ. The emission cloud surrounding this droplet is denoted by the white arrow pointing right in this and subsequent frames. It is very close to the central axis of the ICP. In Frame 691, the cloud

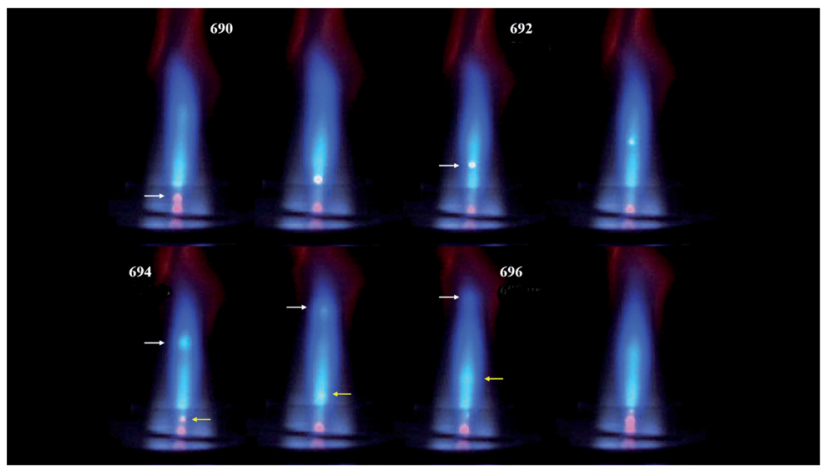

Fig. 1 Successive frames from a small section of Video 1. $\uparrow$ Frame 690 is the first image from this clip. Alternate frames are numbered in the order they were measured. The time interval between frames was 200 $\mu \mathrm{s}$. A white arrow pointing right denotes the first droplet cloud under discussion. The yellow arrow pointing left denotes the second such droplet.

of material around this droplet can be seen isolated against the blue NAZ. Of course, what is observed in Fig. 1 is the emission cloud surrounding the droplet, not the droplet itself. ${ }^{4}$ This cloud in Frame 691 has a dark red core, which we believe to be primarily YO emission, ${ }^{28,29}$ from comparison with the appearance of the outer fringes of the axial channel upstream inside the torch. The dark red center of this cloud is approximately $1 \mathrm{~mm}$ in diameter. The central core is surrounded by pale red emission, ascribed to neutral $\mathrm{Y}$ emission. ${ }^{28,29}$ This neutral $\mathrm{Y}$ cloud is approximately $2 \mathrm{~mm}$ diameter.

In Frame 692 the droplet cloud morphology remains the same, and the droplet cloud has contracted and moved downstream. In Frame 693 the droplet cloud has shrunk further and is now just a pale red, or even white, cloud. This cloud continues downstream and expands further in Frames 694 and 695. It appears that what was initially a wet droplet cloud has been converted into a blue cloud surrounding a solid particle. This particle cloud dissipates in Frame 696; a spherical blue cloud of $\mathrm{Y}^{+}$emission is just visible at the position expected from the aforementioned particle. The blue particle cloud has blended into the background NAZ entirely in Frame 697.

Returning to Frame 694, the yellow arrow pointing left indicates a second red droplet cloud upstream of the one just discussed. This droplet cloud is slightly off-center but still well within the axial channel of the ICP. The corresponding cloud expands and evolves into a fuzzy white cloud in Frame 695, followed by a diffuse white distortion in Frame 696. The observation that this droplet-type emission cloud dissipates in only two frames $(400 \mu \mathrm{s})$ means that this droplet is apparently not as large as the one discussed previously. Furthermore, the axial channel is probably hotter off-center than on-center in its upstream reaches inside or just downstream from the load coil. ${ }^{10}$ Therefore, this second droplet heats and the resulting cloud dissipates faster than the one denoted by the white arrows.

All frames have a fuzzy white zone on-center, in the middle of blue $\mathrm{Y}^{+}$emission in the NAZ. We believe this "streaky" zone is 
due to cooling of the plasma by passage of solid residues of numerous small or medium-sized droplets that have already been desolvated at a range of axial positions upstream in the axial channel. Note that this "streaky" zone is right where the sampling cone of a MS would normally be situated. If there were solid particles still present at this location, they would be extracted into the sampler along with the corresponding atoms and ions. The particles right along the central axis would even go through the skimmer toward the first ion lenses. Such solid deposition is indeed observed in ICP-MS and is a likely cause of drift and instability. Modern quadrupole instruments incorporate at least one, and as many as four, $90^{\circ}$ bends in the ion optics to minimize the deleterious effects of this deposition.

Both Video $1 \dagger$ and Fig. 1 also display a wispy red plume at the downstream end of the plasma due to YO emission. Yttrium oxide is recreated at the end of the plasma by reaction between $\mathrm{Y}^{+}$ions and $\mathrm{O}_{2}$ from entrained air, which cools the plasma and increases the gas density of $\mathrm{O}_{2}$ and $\mathrm{O}$ atoms. This YO cloud exhibits the swirls and eddies seen previously. This entrainment of air causes the familiar audible "whine" of the ICP..$^{21,22}$

The droplet/particle velocity in the axial channel can also be estimated from these photos. The luminous outer section of the plasma at the far upstream end, i.e., just above the top turn of the load coil, is approximately $16 \mathrm{~mm}$ wide. Using this distance as a calibrant, the droplet denoted by the white arrows travels $\sim 22 \mathrm{~mm}$ to the downstream tip of the plasma in Frames 691 to 695,4 frames or $800 \mu \mathrm{s}$. The flow velocity is $22 \mathrm{~mm} / 0.80 \mathrm{~ms}=$ $28 \mathrm{~m} \mathrm{~s}^{-1}$. This velocity value is very close to our previous measurement $t^{23,24}$ of $27 \mathrm{~m} \mathrm{~s}^{-1}$ and is in reasonable agreement with the values of $30-35 \mathrm{~m} \mathrm{~s}^{-1}$ determined by Cicerone and Farnsworth. ${ }^{6}$

\section{Conflicts of interest}

There are no conflicts of interest to declare.

\section{Acknowledgements}

Research at the Ames Laboratory was supported by the U.S. Department of Energy-National Nuclear Security Agency under contract number DE-AC02-07CH11358. Funding was provided by the U.S. Department of Energy, Office of Nuclear Nonproliferation (NA-22).

\section{References}

1 G. M. Hieftje and H. V. Malmstadt, Anal. Chem., 1968, 40, 1860-1867.

2 N. C. Clampitt and G. M. Hieftje, Anal. Chem., 1972, 44, 12111219.

3 J. A. Horner and G. M. Hieftje, Spectrochim. Acta, Part B, 1998, 53, 1235-1259.

4 J. W. Olesik, Appl. Spectrosc., 1997, 51, 158A-175A.

5 J. W. Olesik, J. A. Kinzer and G. J. McGowan, Appl. Spectrosc., 1997, 51, 607-616.
6 M. T. Cicerone and P. B. Farnsworth, Spectrochim. Acta, Part $B, 1989$, 44, 897-907.

7 C. M. Benson, J. Zhong, S. F. Gimelshein, D. A. Lewin and A. Montaser, Spectrochim. Acta, Part B, 2003, 58, 1453-1471.

8 A. Murtazin, S. Groh and K. Niemax, Spectrochim. Acta, Part $B, 2012,67,3-16$.

9 L. Flamigni, J. Koch and D. Günther, Spectrochim. Acta, Part $B, 2012,76,70-76$.

10 M. Aghaei and A. Bogaerts, J. Anal. At. Spectrom., 2017, 32, 233-261.

11 J. Fuchs, M. Aghaei, T. D. Schachel, M. Sperling and A. Bogaerts, Anal. Chem., 2018, 90, 10271-10278.

12 D. R. Bandura, V. I. Baranov, O. I. Ornatsky, A. Antonov, R. Kinach, X. Lou, S. Pavlov, S. Vorobiev, J. E. Dick and S. D. Tanner, Anal. Chem., 2009, 81, 6813-6822.

13 O. Ornatsky, D. R. Bandura, V. Baranov and S. D. Tanner, J. Immunol. Methods, 2010, 361, 1-20.

14 F. Li, D. W. Armstrong and R. S. Houk, Anal. Chem., 2005, 77, 1407-1413.

15 C. Degueldre, P.-Y. Favarger and C. Bitea, Anal. Chim. Acta, 2004, 518, 137-142.

16 I. Moreels, K. Lambert, D. De Muynck, F. Vanhaecke, D. Poelman, J. C. Martins, G. Allan and Z. Hens, Chem. Mater., 2007, 19, 6101-6106.

17 A. R. Montoro Bustos, J. R. Encinar, M. T. FernandezArguelles, J. M. Costa-Fernandez and A. Sanz-Medel, Chem. Commun., 2009, 3107-3109.

18 C. C. Garcia, A. Murtazin, S. Groh, V. Horvatic and K. Niemax, J. Anal. At. Spectrom., 2010, 25, 645-653.

19 B. Franze, I. Strenge and C. Engelhard, J. Anal. At. Spectrom., 2017, 32, 1481-1489.

20 D. Mozhayeva and C. Engelhard, J. Anal. At. Spectrom., 2020, DOI: 10.1039/c9ja00206e.

21 R. K. Winge, D. E. Eckels, E. L. DeKalb and V. A. Fassel, J. Anal. At. Spectrom., 1988, 3, 849-855.

22 R. K. Winge, J. S. Crain and R. S. Houk, J. Anal. At. Spectrom., 1991, 6, 601-604.

23 R. S. Houk, R. K. Winge and X. Chen, J. Anal. At. Spectrom., 1997, 12, 1139-1148.

24 D. B. Aeschliman, S. J. Bajic, D. P. Baldwin and R. S. Houk, J. Anal. At. Spectrom., 2003, 18, 1008-1014.

25 R. H. Scott, V. A. Fassel, R. N. Kniseley and D. E. Nixon, Anal. Chem., 1974, 46, 75-80.

26 A. Montaser, M. G. Minnich, H. Liu, A. G. T. Gustavson and R. F. Browner, Fundamental Aspects of Sample Introduction in ICP Spectrometry, in ICP Mass Spectrometry, ed. A. Montaser, Wiley-VCH, 1998, p. 366.

27 S. R. Koirtyohann, J. S. Jones and D. A. Yates, Anal. Chem., 1980, 52, 1965.

28 K. P. Li, M. Dowling, T. Fogg, T. Yu, K. S. Yeah, J. D. Hwang and J. D. Winefordner, Anal. Chem., 1988, 60, 1590-1599.

29 R. S. Houk, Instrumentation for ICP-MS, in Handbook of ICP$M S$, ed. K. E. Jarvis, A. L. Gray and R. S. Houk, Viridian, 1992, ch. 2 . 